\title{
Effects of asynchronized generators on emergency modes of power mains with inferior power quality
}

\author{
Yuri Bulatov ${ }^{1, *}$, Andrey Kryukov ${ }^{2,3}$, and Edward Shumansky ${ }^{1}$ \\ ${ }^{1}$ Bratsk State University, Department of Electric Power and Electrical Engineering, Bratsk, Russia \\ ${ }^{2}$ Irkutsk State Transport University, Department of Transport Electric Power, Irkutsk, Russia \\ ${ }^{3}$ Irkutsk National Research Technical University, Department of Power Supply and Electrical Engineering, Irkutsk, Russia
}

\begin{abstract}
Application of asynchronized generators (ASG) in distributed generation plants allows to obtain the following positive results: increase stability margins; expand reactive power adjustment ranges; simplify processes of synchronization to line due to possibility of frequency and EMF phase control; ensure the unit's operation in synchronous mode when one of excitation windings is damaged. The work provides description of the developed ASG computer model and the system of excitation automatic control. The studies are conducted in the MATLAB system using the Simulink and SimPowerSystems software packages. Emergency modes were simulated for the mains with ASG-based distributed generation plants in conditions of inferior power quality. ASG influence on emergency modes and levels of harmonic distortions in the mains were determined.
\end{abstract}

\section{Introduction}

Application of distributed generation (DG) with advanced control system and building smart electrical energy systems (EES) with active-adaptive network is the vector of development in the contemporary electricpower engineering. DG plants can be built based on synchronous (SG) and asynchronized generators (ASG) [1]. Asynchronized machines can operate not only in delivery modes, but also in modes of significant reactive power consumption [1-3], which allows to increase the EES stability and controllability. In addition, ASG possess a number of adaptive features ensuring the following positive results at their application [1-4]: enhancing the efficiency of DG plants and stability of their parallel operation; wider ranges of reactive power adjustment; improvement of synchronization to line, etc.

Asynchronized generators can be used both for traditional thermal power plants and hydraulic power plants (HPP) of high and mid power, and for wind power generation plants and for tidal power plants [6], as well as in frequency electromechanical converters [7].

The asynchronized generator is a type of doubly fed machine [8]. Its main difference from the synchronous generator is the presence of several excitation windings shifted relative to each other and connected to an alternating current source [9].

The article describes the developed computer model of high-voltage ASG with an automatic excitation control system (AEC) using IGBT transistors and a proportional-integral-differential (PID) rotor frequency controller. Emergency modes were simulated for the mains with distributed generation plants based on ASG and $\mathrm{SG}$ in conditions of inferior power quality. Effect of ASG on EES emergency and post-emergency modes and levels of harmonic distortions was determined. Multiple experiments conducted allowed to determine the effect of the proposed AEC system on stability and efficiency of ASG operation during power mains failures.

\section{Description of ASG model and the mains under consideration}

A circuit with two DG plants based on turbine generating units with SG or ASG was studied (fig. 1). The mains under study was operating using inferior power quality with respect to harmonicity of voltage and current curves. Parallel operation of DG plants through transformers and overhead power lines (OPL) with EES of $35 \mathrm{kV}$ was assumed as reference conditions. Threephase fault on OPL1 and its disconnection on two sides in $0.1 \mathrm{~s}$ were assumed as the emergency mode.

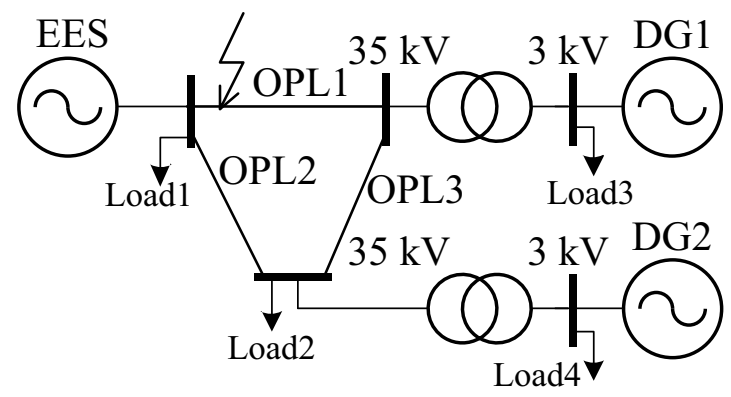

Fig. 1. The diagram of the mains under study.

\footnotetext{
* Corresponding author: bulatovyura@yandex.ru
} 
The studies were conducted in the MATLAB system using the Simulink and SimPowerSystems software packages. Fig. 2 provides a diagram of the model invented for study of ASG influence on the emergency modes in conditions of inferior power quality. It included models of the following elements (fig. 2): asynchronous machine (unit ASG $1000 \mathrm{~kW}$ ); excitation system (Excitation system unit for ASG); a turbine
(Steam Turbine unit); voltage and speed controllers (PID Controller units); active-inductive load (Load units); equivalent high-power EES (System $35 \mathrm{kV}$ unit); measuring instruments, filters and oscilloscopes; $35 \mathrm{kV}$ power lines (Line units); $3 / 35 \mathrm{kV}$ power transformers (3/35 kV Transformer units); and the source of voltage curves harmonicity distortions (Three-Phase Programmable Voltage Source unit).

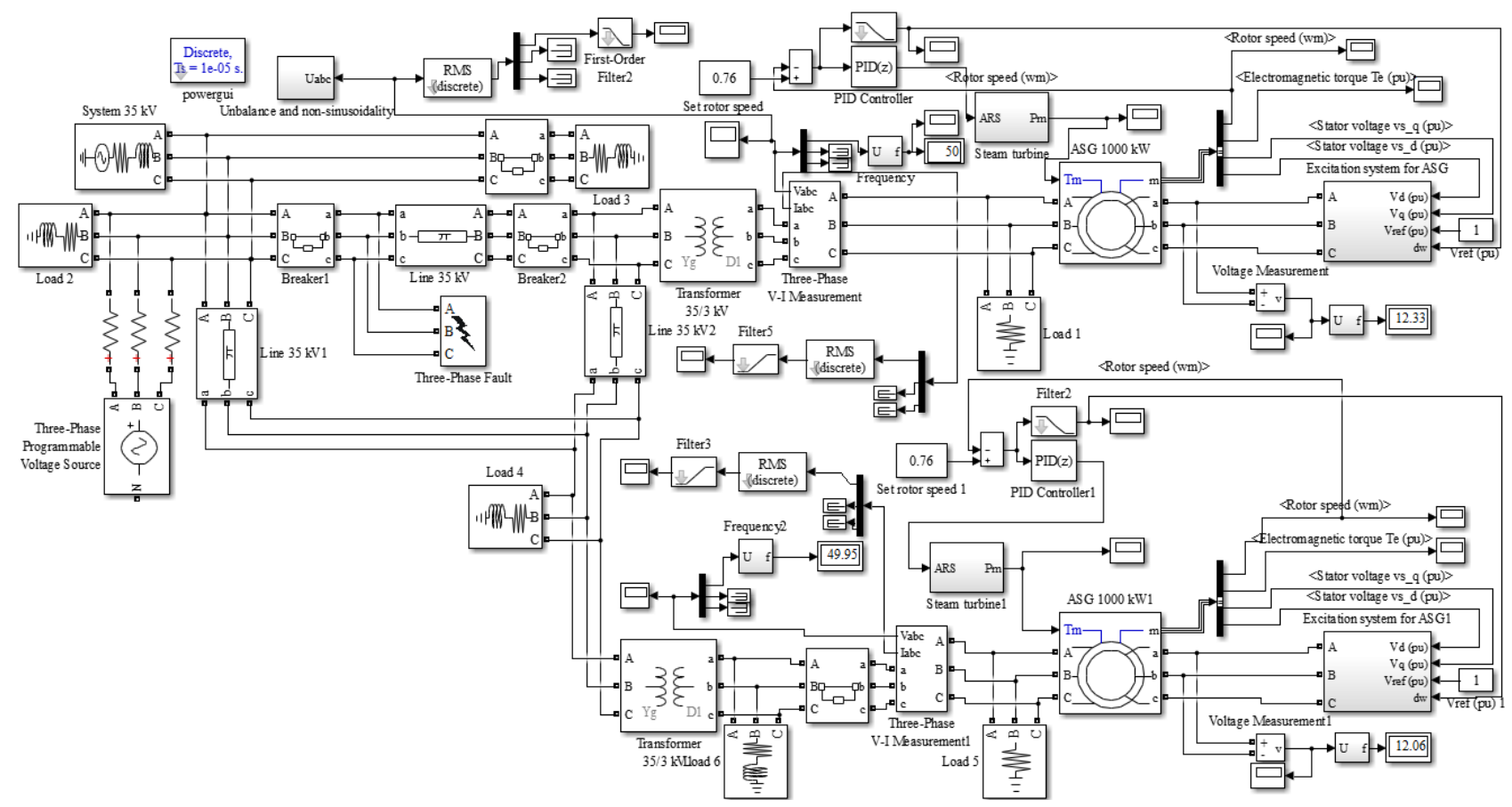

Fig. 2. The diagram of the mains under study model in Matlab.

The 3-rd and 5-th harmonics generation in EES node was simulated. Oscillograms of voltage signal on EES buses and its harmonic composition are shown in fig. 3 .

A controlled inverter that receives power from the DC voltage source is proposed to be used as the ASG excitation system in the model. The inverter, built on IGBT transistors, generated sinusoidal voltage with $12 \mathrm{~Hz}$ frequency which was received by the ASG rotor

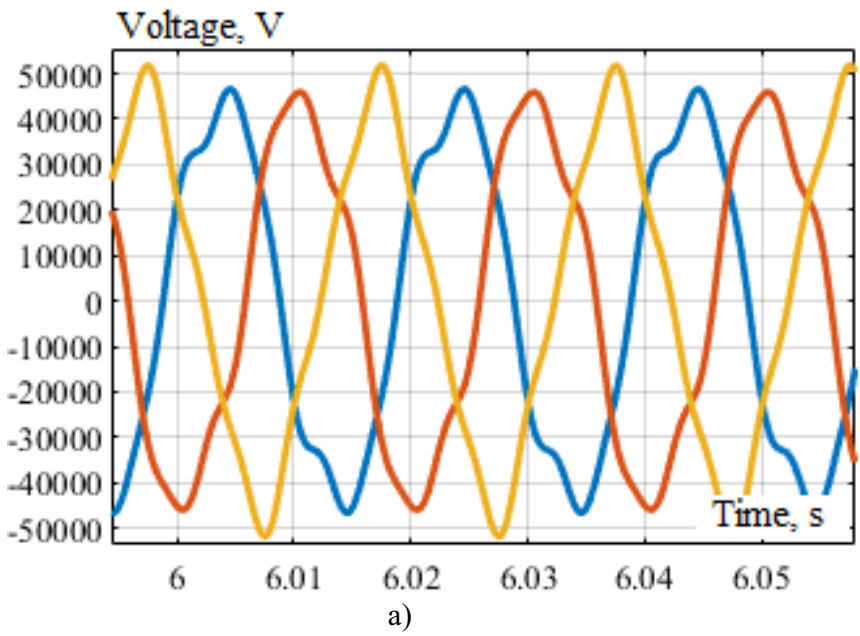

three-phase winding. The diagram of the ASG excitation system model with regulators built in MATLAB, is shown in Fig. 4.

The voltage on the ASG stator winding calculated based on the longitudinal and transverse components, was compared with the set setpoint and the deviation was transmitted to PID controller (PID controller unit in Fig. 4).

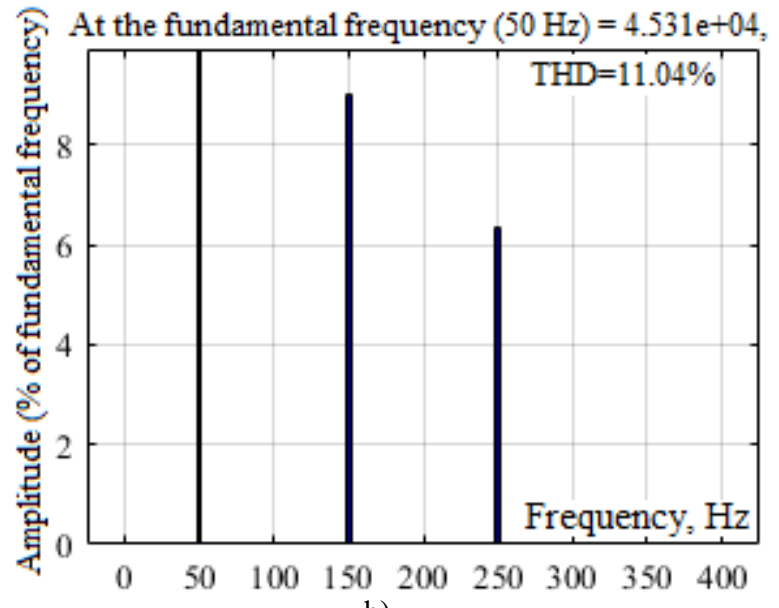

b)

Fig. 3. Voltage oscillograms in EES node (a) and harmonics composition in the mains under study (b). 


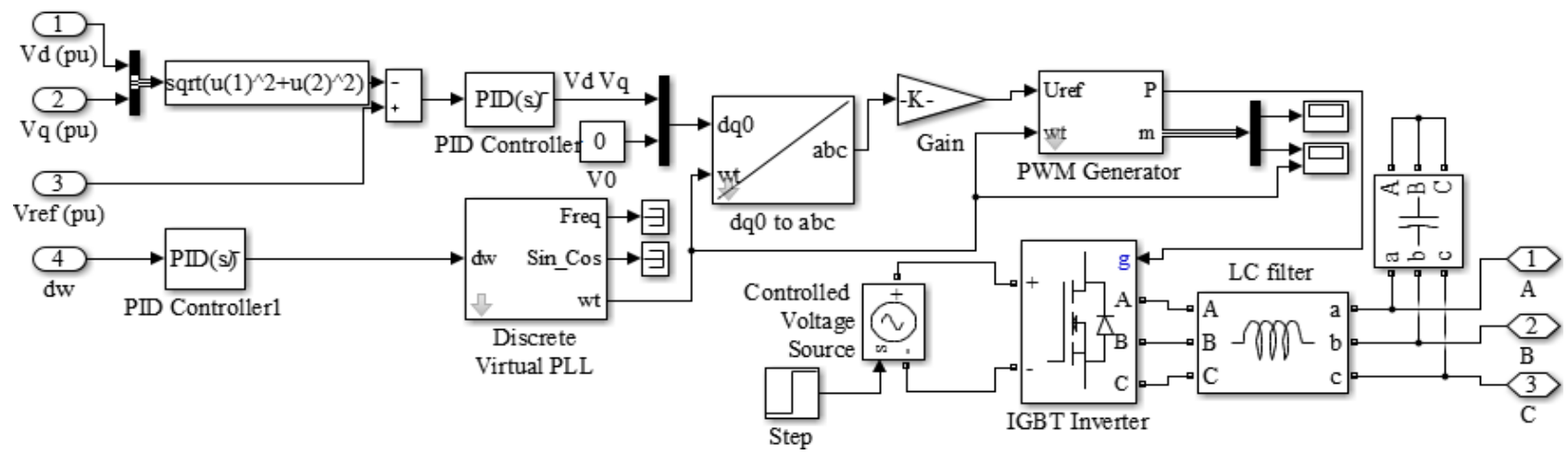

Fig. 4. The model diagram of the ASG excitation system in MATLAB.

Then, using the special units (Discrete Virtual PLL, abc to dq0 in Fig. 4) sinusoidal voltages were generated that were transmitted to the control signals generator with pulse-width modulation (PWM Generator). In order to control the frequency of the voltage generated by the inverter, the use of frequency deviation signal was provided for, which was further added to a reference frequency of $12 \mathrm{~Hz}$ Discrete Virtual PLL unit. The positive influence of ASG [4] rotor winding voltage frequency $f_{P}$ control signal was shown below. The frequency calculated in this way was the master frequency for the control signals generator. After this, the signals generator formed control pulses for the inverter IGBT transistors (IGBT Inverter in fig. 4). Three-phase voltage was applied on ASG rotor winding from the inverter after the LC-filter.

To maintain a set rotational frequency of the generator rotor PID controller was applied (PID controller unit in Fig.1) that was affecting the turbine. The following ASG parameters were used for simulation: rated power $P_{r}=1000 \mathrm{~kW}$; synchronous frequency rate $n_{0}=1000 \mathrm{rpm}$; efficiency factor $\eta=95.5 \%$; power factor $\cos \varphi=0.858$; rated voltage $U=3 \mathrm{kV}$; rated current $I=118 \mathrm{~A}$; locked rotor current ratio 6.3; starting torque ratio 1.2 ; number of poles pairs $p=3$.

Mathematical model of steam turbine used in DG plants is represented with the following transfer function:

$$
W(s)=\frac{P_{T}}{\mu}=\frac{1}{T_{T} s+1}
$$

where $P_{T}$ - the turbine mechanical power; $\mu$ - opening of a control unit; $T_{T}$ - time constant of the turbine, determined by the delay in the conversion of energies (assumed to be $0.2 \mathrm{~s}$ ); $s$ - a complex variable.

\section{Simulation results}

The emergency mode was simulated as a result of a three-phase fault and disconnection of OPL1 (fig. 1); in this case, SG and ASG influence on power quality indices (PQI) and transient processes in EES were compared. To compare with ASG, a standard model of synchronous machine from SimPowerSystems package with similar parameters was used. At SG simulation, AEC and automatic speed controller (ASC) operating under PID law, were used, whose detailed description is given in works $[10,11]$. AEC and ASC tuning was carried out using PID Tuner program of automatic tuning of MATLAB system Simulink Control Design package.

Simulation results indicated that the use of ASG in DG plants allows to enhance power quality in the normal and post-emergency modes. Voltage harmonics factors in various operating modes of the mains are provided in table 1.

Table 1. PQI in the mains under study on $3 \mathrm{kV}$ buses.

\begin{tabular}{|l|l|l|l|}
\hline \multirow{2}{*}{ Mains operation mode } & \multicolumn{3}{|c|}{ Voltage harmonics factor, \% } \\
\cline { 2 - 4 } & $k_{U a}$ & $k_{U b}$ & $k_{U c}$ \\
\hline 1. Without DG plants & 11.02 & 11.02 & 11.02 \\
\hline $\begin{array}{l}\text { 2. With DG plants } \\
\text { based on SG }\end{array}$ & 9.27 & 9.27 & 9.27 \\
\hline $\begin{array}{l}\text { 3. With DG plants } \\
\text { based on ASG }\end{array}$ & 6.58 & 6.58 & 6.58 \\
\hline
\end{tabular}

The time dependences of voltage on DG1 plant buses in emergency and post-emergency modes are provided in fig. 5. Graphs for the rotor rotational frequency and generator voltage deviations when using SG or ASG, are provided in fig. 6. For DG2 plant the graphs are similar. When using synchronous generators, the loss of stability, significant voltage dips (fig. 6, b), rotor rotational frequency fluctuations (fig. 6, a) and frequency in the mains (fig. 7) are observed. When using ASG with the proposed AEC system, one manages to ensure stability and maintain the set levels of voltage and frequency (fig. 6, 7) in all modes under consideration. The comparison of ASG and SG in the course of simulation indicated a significant increase in the asynchronized generator stability margins.

The efficiency of using the frequency deviation signal for its adjustment on ASG rotor winding is provided in fig. 8 when ASG2 connection to the mains by self-synchronizing method was simulated. Maximum deviation of ASG rotor rotation frequency from the rated value is reduced by $4 \%$, and voltage dip is decreased by $2 \%$. In this case, oscillability and transition process time for voltage and frequency are reduced.

A similar effect is observed in emergency and postemergency modes for ASG parameters adjustment when AEC signal is used for changing voltage frequency on rotor winding. By way of example, fig. 9 provides oscillograms of ASG rotor rotational frequency deviation in the emergency mode. When using the frequency deviation signal in the excitation control system, the rotor rotational frequency deviation is reduced by $14 \%$. 


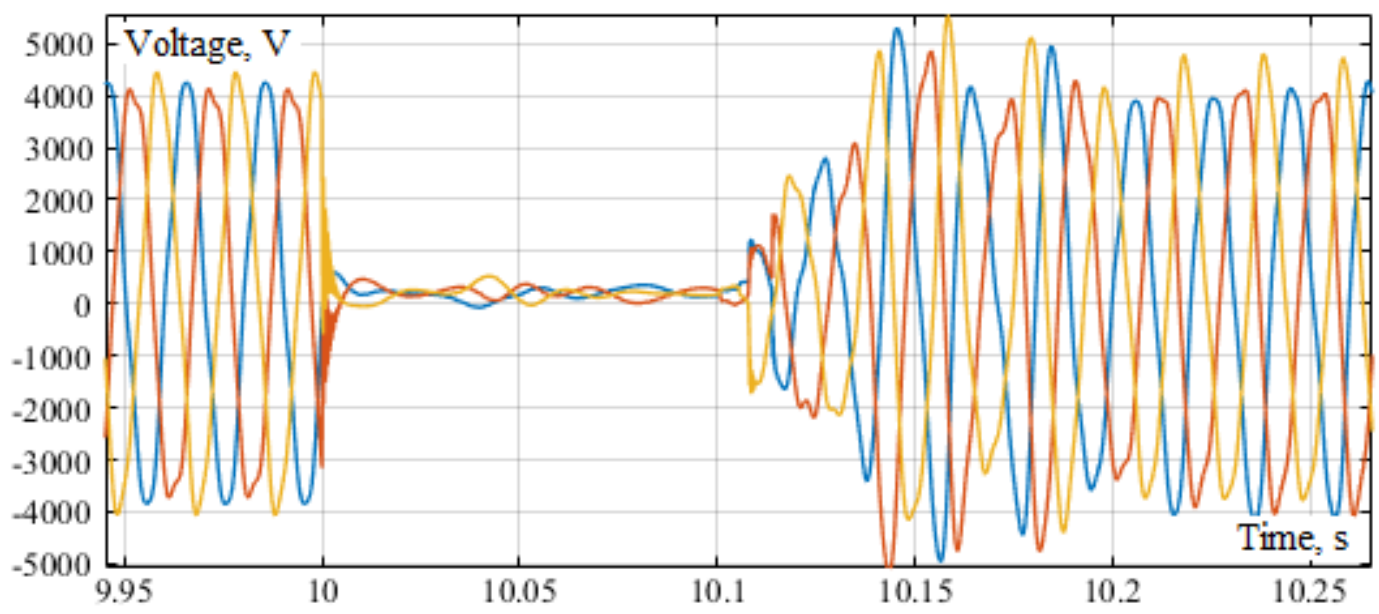

a) ASG were used

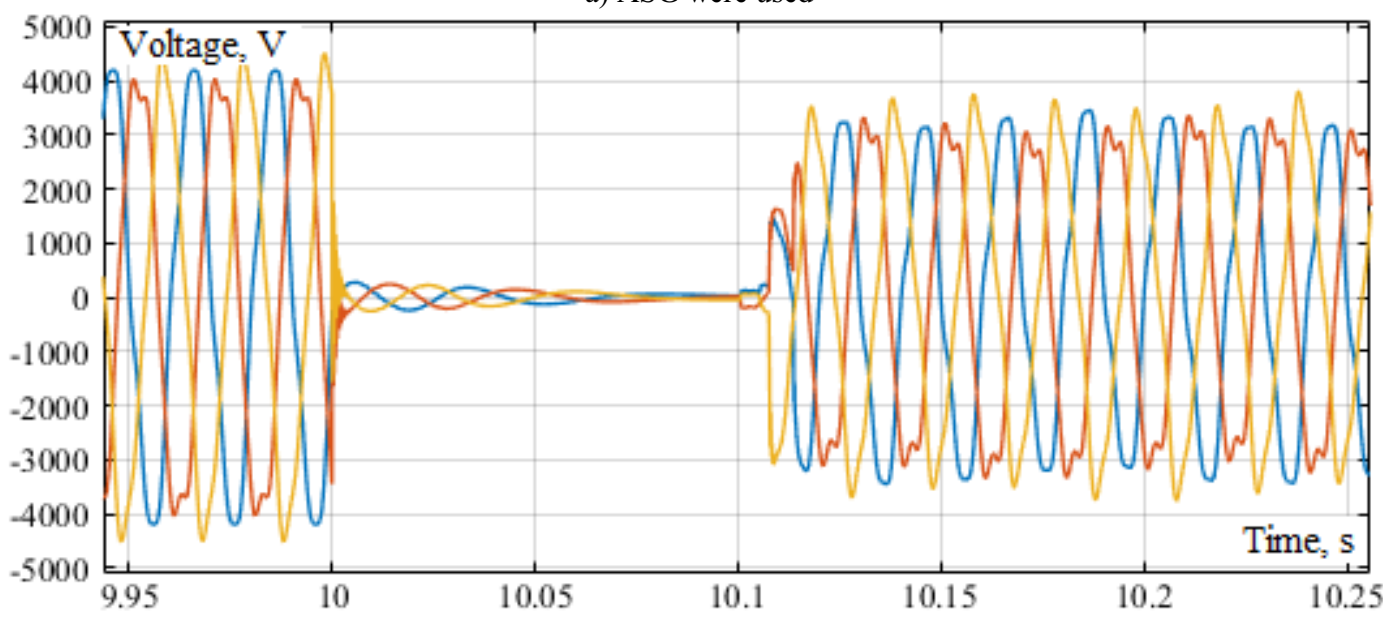

b) SG were used

Fig. 5. Time dependences of DG 1 plant generator voltage.

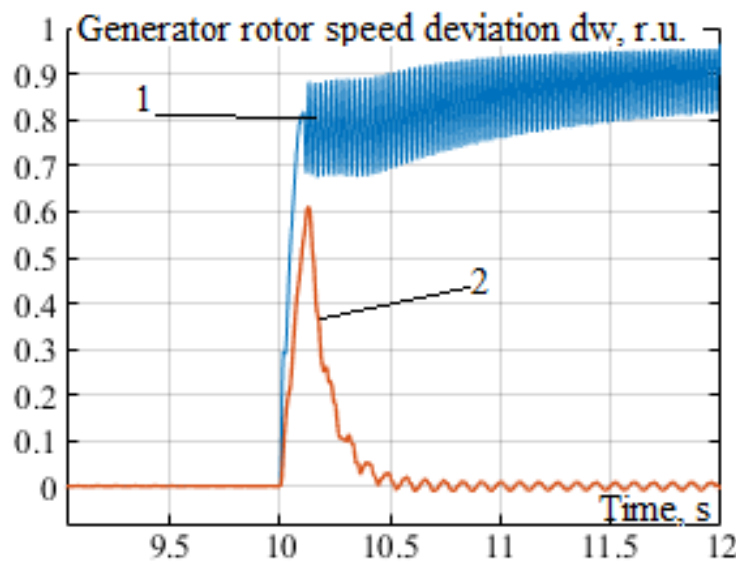

a)

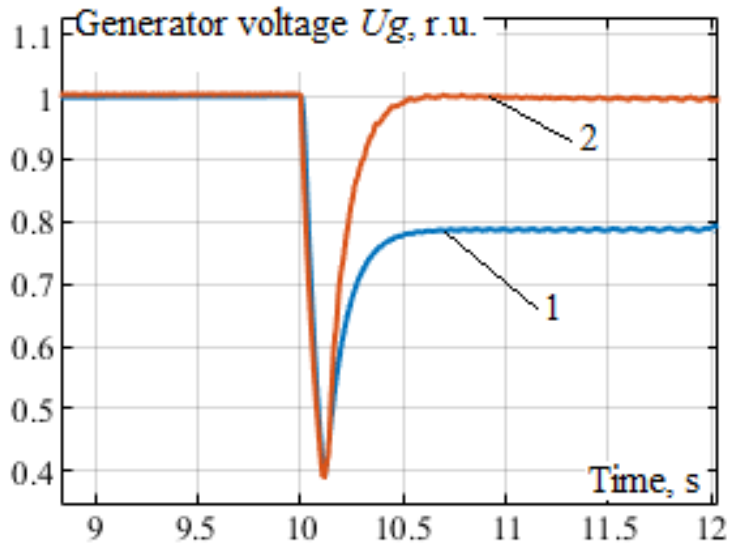

b)

Fig.6. Oscillograms of rotor rotation frequency deviation from the rated rotor rotational frequency (a) and DG plant generator voltage (b) in conditions of line short circuit and its disconnection by protection: 1 - SG was used; 2 - ASG was used.

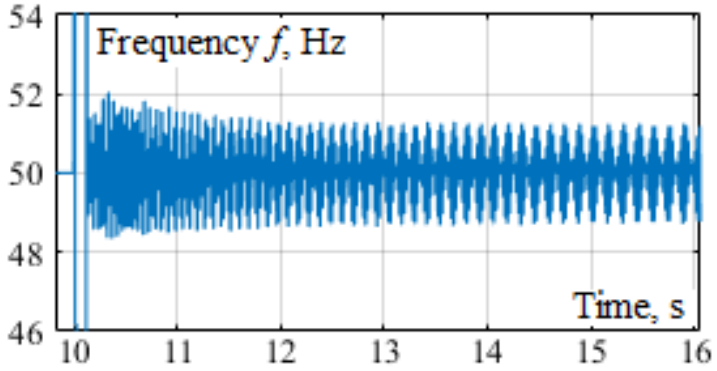

a) when SG was used

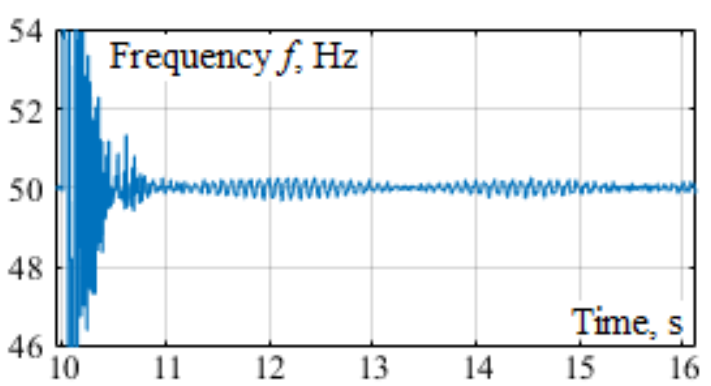

b) when ASG was used

Fig.7. Frequency oscillograms in the mains in conditions of line short circuit and its disconnection by protection. 


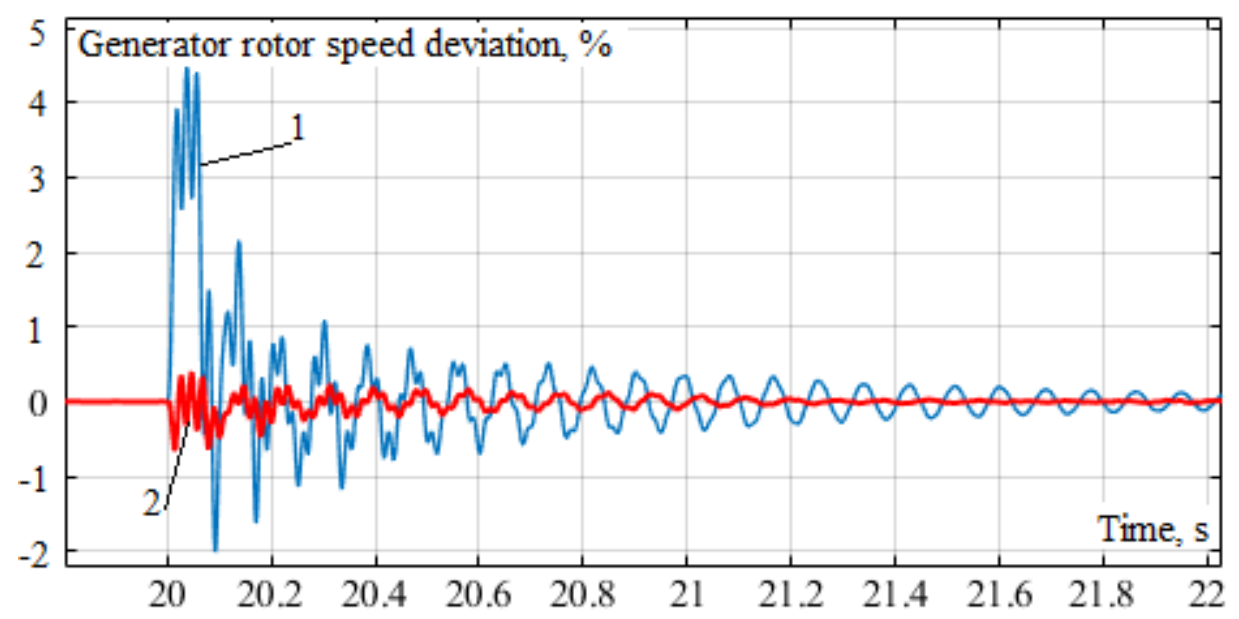

a)

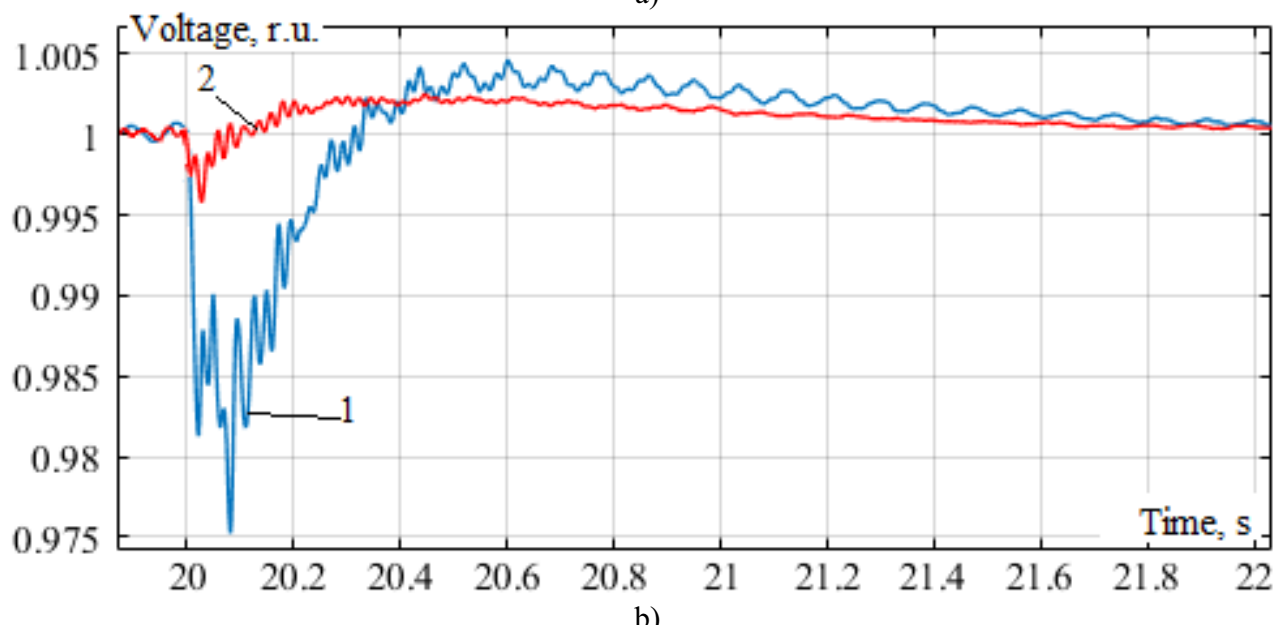

b)

Fig.8. Oscillograms of rotor speed deviation (a) and voltage (b) of ASG2 when it is connected to the mains by self-synchronizing method: 1 - without changing voltage on rotor winding; 2 - frequency on rotor winding was changed automatically.

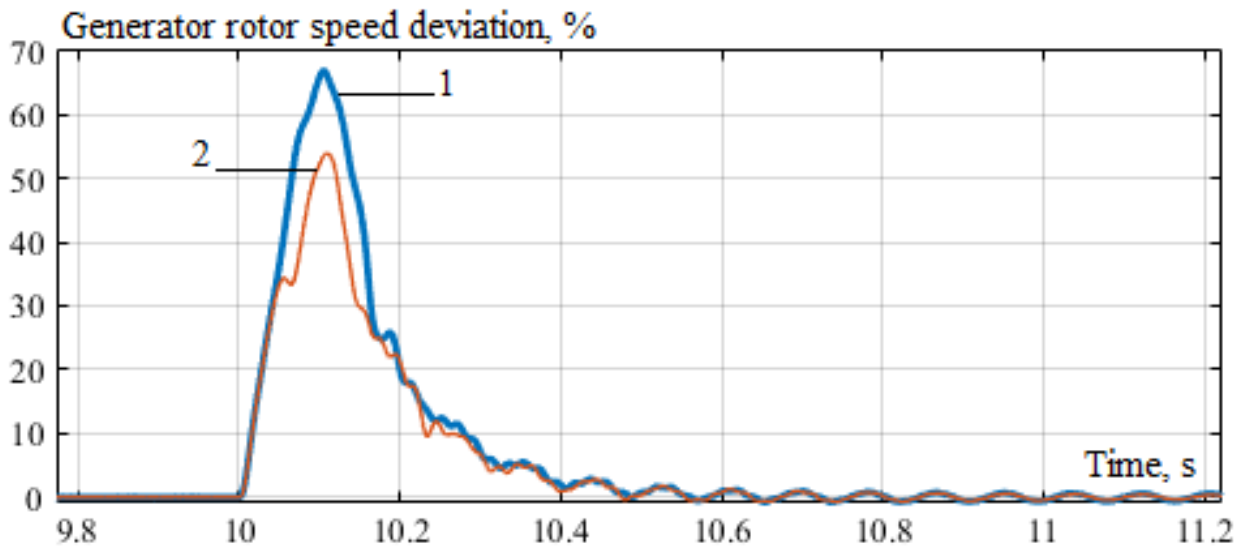

Fig.9. Oscillograms of ASG rotor speed deviation in conditions of line short circuit and its disconnection by protection: 1 - without change of frequency on the rotor winding; 2 - automatic control of frequency on the rotor winding.

In general, simulation results indicated that using ASG and the proposed AEC system on IGBT transistors with possibility of voltage frequency control on rotor winding, in the distributed generation plants, smooth change of the set parameters is ensured, thus significantly reducing voltage and frequency fluctuations in the mains. It should be noted, that optimal tuning of parameters of the proposed AEC and ASC of the asynchronized generator, would allow to obtain an additional effect with regard to enhancing stability and quality of the mains parameters adjustment with DG plants based on ASG.

\section{Conclusion}

The computer modeling results allow us to make the following conclusions:

1. The use of ASG in DG plants improves power quality in normal and post-emergency operating modes of the mains. 
2. Comparison of ASG and SG operating modes in conditions of inferior power quality indicated higher stability margins of the asynchronized generator.

3. Using the mains frequency deviation signal to change the frequency of voltage supplied from the inverter to ASG rotor winding, allows to enhance the efficiency of voltage and ASG rotor speed when it is energized from the mains by the self-synchronizing method: maximum deviation of ASG rotor speed from the rated value is reduced by $4 \%$, and voltage dip is decreased by $2 \%$. A similar effect is observed in emergency and post-emergency modes when voltage frequency is changed on the rotor winding.

4. Asynchronized generators can be effectively used in the distributed generation plants. Optimization of the proposed asynchronized generator AEC and ASC system parameters tuning would allow to obtain an additional effect with respect to increase in stability and quality of the parameters adjustment of the mains with DG plants based on ASG.

The research was carried out with financial support from a grant from the state assignment of the Ministry of Science and Higher Education of Russia (project No. 0667-2020-0039).

\section{References}

1. I.A. Labunets, Asynchronized turbogenerators. New technologies in the energy sector. Moscow: UES of Russia, 139-144 (2002)

2. G.A. Dmitrieva, S.N. Makarovsky, and A.Yu. Pozdnyakov, Prospects for the use of asynchronized turbogenerators in the European zone UES of Russia, Electric stations, 8, 35-43 (1997)

3. Yu.G. Shakaryan, I.A. Labunets, and P.V. Sokur, Expediency and prospects of equipping power plants with asynchronized turbo and hydro generators, Electricity-2002, 42, 35-43 (2003)
4. Yu.N. Bulatov, A.V. Kryukov, E.K. Shumansky Control of power supply system modes with distributed generation plants based on asynchronized machines. Science bulletin of the Novosibirsk state technical university, 78, 175-188 (2020)

5. Yu.M. Golodnov and A.B. Pikovsky, Results of science and technology. Unconventional and renewable energy sources. Generators for wind, small hydraulic and tidal power plants (Moscow: VINITI, 2012)

6. A. Bocquel, J. Janning, Analysis of a $300 \mathrm{MW}$ Variable Speed Drive for Pump- Storage Plant Applications, EPE, 1, 1-10 (2005)

7. R.S. Tsgoev, Non-synchronous parallel operation of the OES of Siberia and the East, Electro, 1, 4-6 (2004)

8. Yu.G. Shakaryan, Asynchronous synchronous machine (Moscow: Energoatomizdat, 1984)

9. Yu.N. Garaev, E.K. Lokhanin, and E.L. Rossovsky, Differences between synchronous machines of longitudinal-transverse excitation from asynchronized synchronous machines, News of the Scientific and Technical Center of the Unified Energy System, 73, 88-96 (2005)

10. Yu.N. Bulatov, A.V. Kryukov, Optimization of automatic regulator settings of the distributed generation plants on the basis of genetic algorithm. 2nd International Conference on Industrial Engineering, Applications and Manufacturing (ICIEAM). IEEE Conference Publications (2016)

11. A.V. Kryukov, S.K. Kargapol'cev, Yu.N. Bulatov, O.N. Skrypnik, B.F. Kuznetsov, Intelligent control of the regulators adjustment of the distributed generation installation. Far East Journal of Electronics and Communications, 5, 1127-1140 (2017). 